\title{
Activity patterns in the reintroduced Pyrenean brown bear population
}

\author{
Aida Parres ${ }^{1}$ (D) - Santiago Palazón ${ }^{2}$ • Ivan Afonso ${ }^{3}$ - Pierre-Yves Quenette ${ }^{4}$ - Antoni Batet ${ }^{2}$ • Jean-Jacques Camarra ${ }^{4}$. \\ Xavier Garreta ${ }^{5}$. Salvador Gonçalves ${ }^{3}$. Jordi Guillén ${ }^{5}$. Sergio Mir $^{3}$ • Ramón Jato ${ }^{6}$ - Joan Rodríguez ${ }^{3}$. \\ Jerome Sentilles ${ }^{4} \cdot$ Laura Xicola $^{7} \cdot$ Yolanda Melero $^{8}$
}

Received: 2 September 2019 / Accepted: 13 May 2020 / Published online: 1 June 2020

(C) The Author(s) 2020

\begin{abstract}
Mammals usually adjust behavioral patterns when exposed to disturbances. Elusiveness and low-risk time selection may reduce their stress in periods of highest risk. In Europe, brown bears (Ursus arctos) coexist with humans in densely populated and modified landscapes and, consequently, are exposed to human-caused disturbances during the daytime hours. Furthermore, intraspecific interactions might also influence their behavioral responses, especially during the mating season. Activity patterns of several large carnivores have been thoroughly studied; however, research is scarce for relocated populations. Here, we report the activity patterns in the reintroduced brown bear population in the Pyrenees. We expected the bears to reduce their activity depending on the type and level of disturbances. We analyzed individual behavior of both sexes (males, solitary females, and females with offspring) and age groups (adults and subadults) using camera-trap surveys under different types of intraspecific and anthropogenic disturbances. In general, bears were more active during the night (2200-0600 h) and avoided peaks of human activity (1000-1800 h). Furthermore, with the increasing nocturnal disturbance of adult males during the mating season, females with offspring and subadults were more active during daylight. This suggests that vulnerable individuals showed high tolerance for human presence. These results contribute to improve our knowledge of how a threatened and relocated bear population behaves in a human-modified landscape of southern Europe. Further research on this population will be crucial to establish optimal management interventions during translocations, and the prevention of human-bear encounters and conflicts.
\end{abstract}

Keywords Ursus arctos $\cdot$ Behavior $\cdot$ Carnivores $\cdot$ Camera-trapping $\cdot$ Activity patterns $\cdot$ Intraspecific interaction

Communicated by: Krzysztof Schmidt

Aida Parres

aida@iop.krakow.pl

1 Institute of Nature Conservation, Polish Academy of Sciences, Adama Mickiewicza 33, 31120 Cracow, Poland

2 Regional Government of Catalonia, 08017 Barcelona, Spain

3 General Council of Aran (Conselh Generau d'Aran), 25530 Vielha, Lleida, Spain

4 French Agency of Biodiversity, OFB (Office Français de la Biodiversité), 31800 Villeneuve de Rivière, France

5 Brown Bear Foundation, FOP (Fundación Oso Pardo), 39010 Santander, Spain

6 Aragonese Society for Agri-environmental Management (Sociedad Aragonesa de Gestión Agroambiental), 50018 Zaragoza, Spain

7 Autonomous University of Barcelona, 08193 Cerdanyola del Vallès, Spain

8 CREAF, 08193 Cerdanyola del Vallès, Spain

\section{Introduction}

General animal behavior is often described by activity patterns, which can be considered as an integration of several behaviors including movement, foraging, and social interactions. The activity patterns are influenced both by internal (i.e., sex, age, and reproductive status) and external factors (i.e., food availability, human presence, and conspecific interactions) (Leuchtenberger et al. 2014). Behavioral patterns in large carnivores are well documented worldwide, especially for brown bears (Ursus arctos). Radio telemetry and direct observation are the most commonly used methods in Europe and North America. However, monitoring becomes more complicated in low-density populations of elusive animals (Treves and Karanth 2003; Ordiz et al. 2013; Alibhai et al. 2017; Zarzo-Arias et al. 2018).

Many studies found that wild brown bears exhibit a wide variety of activity patterns that influence their survival or 
reproductive output (Fortin et al. 2016; Hertel et al. 2016; Frank et al. 2017). While in North America, brown bears are largely diurnal (Klinka and Reimchen 2002; Munro et al. 2007); European populations predominantly exhibit nocturnal and crepuscular patterns (Olson et al. 1998; Kaczensky et al. 2006; Ordiz et al. 2014; but see Zarzo-Arias et al. 2018). The type and the intensity of disturbances vary seasonally. Consequently, this variation may affect the behavioral responses of individuals (Ordiz et al. 2016). In Europe, human presence and activities and habitat loss have become the principal factors affecting this species, restricting most of the bear distribution to forested and mountainous areas (Martin et al. 2010; Piédallu et al. 2017). However, also these natural areas are affected by high human disturbance, and animals shift their activity away from periods of increased human presence during the daylight (Brook et al. 2012). For example, Scandinavian bears decrease daytime activity in response to encounters with humans in areas of higher road density (Ordiz et al. 2016). Avoidance behavior in human-dominated areas is important for human-wildlife coexistence. Nevertheless, the presence of non-elusive individuals, possibly adapted to humans, increases the risk of persecution and conflicts that might affect the survival of the species. For instance, habituated individuals visiting populated areas are often considered as "conflict bears" and removed from population to reduce risk situations between humans and bears (Swenson 1999; Wiegand et al. 2004). Apart from human pressures, intraspecific predation during the mating season or reproductive competition may influence responses in the behavior of individuals of certain age and sex (Steyaert et al. 2013). In fact, females with offspring and subadults may reduce the risk of predation or conspecific competition by spatiotemporal segregation strategies (Hrdy 1979; Steyaert et al. 2013). Offspring predation in the mating season has been widely described in mammals, including brown bears (Ebensperger 1998; Packer 2001; Dahle and Swenson 2003; McLellan 2005). Many studies showed that females with offspring shift from nocturnal to diurnal activity to decrease the chances of male encounters and the risk of infanticide (Stone et al. 2006; Steyaert et al. 2013). Subadults show similar wariness behavior, often explained by the avoidance of adult and more aggressive or competitive individuals (Kaczensky et al. 2006). Further, behavioral responses are adaptive to the type and intensity of the disturbance. With increasing intensity of the intraspecific disturbance, vulnerable bears become more diurnal, increasing the exposition to humans (Kaczensky et al. 2006; Ordiz et al. 2014) and reducing the avoidance response to human presence (Zarzo-Arias et al. 2018).

Understanding large carnivores' behavior variation should help carnivore conservation, especially in human-dominated landscapes (Ordiz et al. 2016; Zarzo-Arias et al. 2018). Activity patterns of reintroduced groups are still poorly known, like the Pyrenean bear population. This population is isolated and considered as one of the most endangered in Europe (Chapron et al. 2009; Martin et al. 2012), with a minimum of 46 individuals detected in 2017 (see also Sentilles et al. 2018 "Suivi de l'ours brun dans les Pyrénées françaises", Annual report 2018 of ONCFS). Human persecution during the last century almost exterminated the native population. To ensure the survival of the population, 11 translocations from Slovenia have been done since 1996. Under growing population density, the increase of recreational activities in the mountain range, particularly in summer and autumn, may increase chances of human-bear encounters in the area (Sahlén 2013; Fortin et al. 2016; Penteriani et al. 2016). Further, negative social perception, linked to the rising number of attacks on free-ranging livestock and risk of attack on humans, may affect conservational efforts to protect this species in the Pyrenean area (Piédallu et al. 2016; Bombieri et al. 2018). Thus, a better understanding of the temporal patterns of this brown bear population in such a human-modified landscape with high levels of human encroachment should help its conservation and mitigate conflicts (Woodroffe et al. 2005).

As a part of a long term project (2010-2017) of bear monitoring in the Pyrenean Mountains of Spain and France using camera trap surveys, we described, for the first time in Europe, the activity pattern of a reintroduced brown bear population. Our main objective was to assess if activity patterns depending on a given type of disturbance experienced by bears differ between sex and age classes. We expected that the most vulnerable bear class, females with offspring and subadults, segregate in time from those dominant or competitive individuals, as an avoidance strategy during seasons with higher intraspecific disturbance. Furthermore, we expected that exposition to human disturbance might increase the tolerance of bears for humans, boosting the avoidance of nocturnal bears.

\section{Materials and methods}

\section{Study area}

The study was carried out along the brown bear distribution range in Central Pyrenees, between France and Spain (from $44^{\circ} 12^{\prime} \mathrm{N} 7^{\circ} 18^{\prime} \mathrm{W}$ to $41^{\circ} 0^{\prime} \mathrm{N} 3^{\circ} 48^{\prime} \mathrm{E}$, Fig. 1). The $7400-$ $\mathrm{km}^{2}$ study area covers several protected areas of Natura 2000 network and natural parks. Temperatures oscillate between $20{ }^{\circ} \mathrm{C}$ in summer and $-10{ }^{\circ} \mathrm{C}$ in winter. The landscape is characterized by large massifs and valleys with relatively steep slopes, in a range between 1.300 and $2.500 \mathrm{~m}$. More than $40 \%$ of the area is forested, dominated by beech (Fagus sylvatica), silver fir (Abies alba), mixed beech-fir forests, other coniferous forests (Pinus uncinata, Pinus sylvestris, and Picea abies), and deciduous forests composed by oaks (Quercus robur and Quercus pubescens), chestnut (Castanea sativa), hazels (Corylus avellana), and wild cherry (Prunus avium). Further, 
Fig. 1 Distribution of the brown bear population in the Pyrenees (France and Spain)

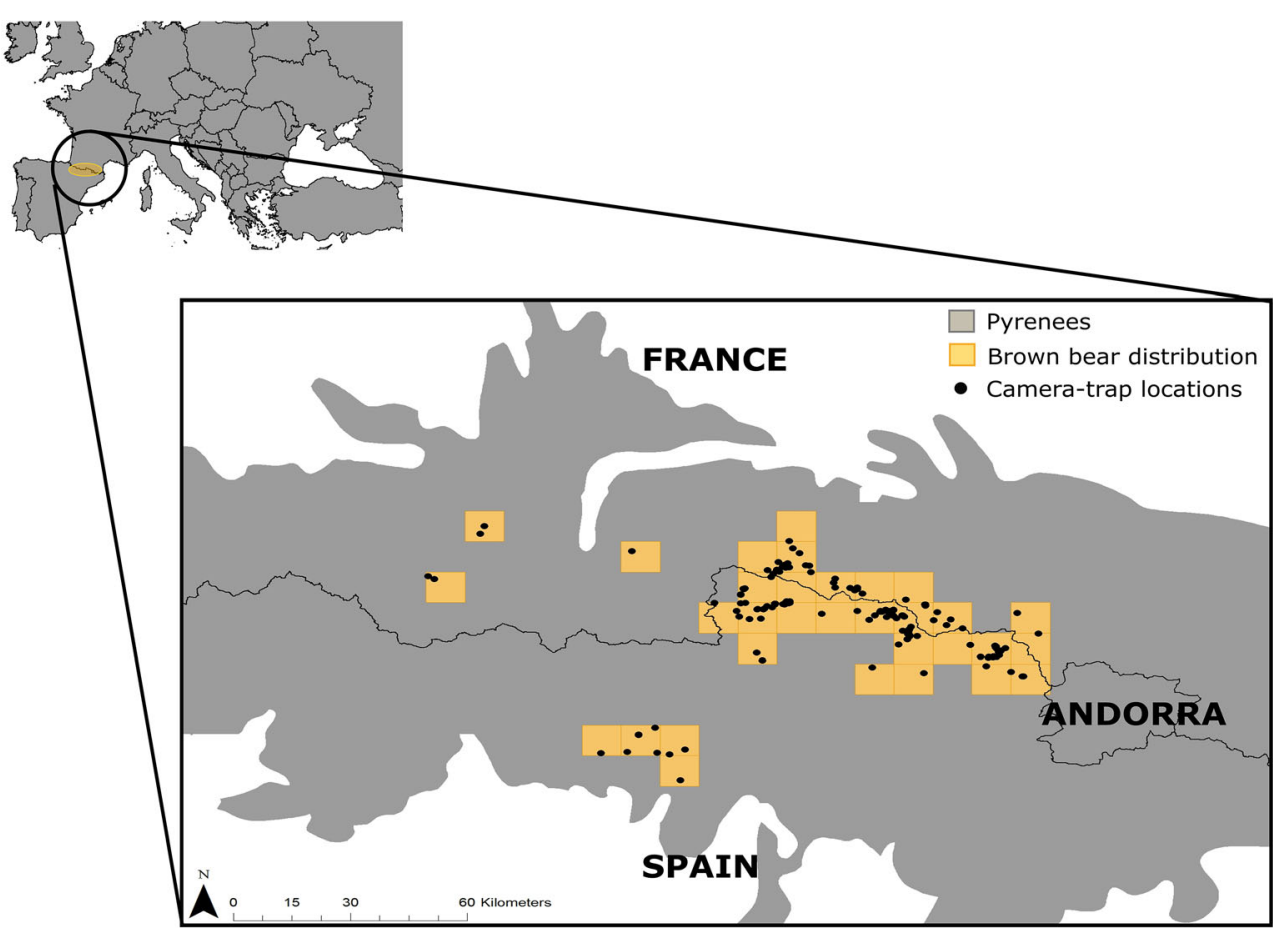

brown bear distribution extends to alpine, subalpine, and montane pastures and scrubs (Martin et al. 2012). Human density in this mountainous area has increased for the last decades, encouraging the development of the farming and beekeeping sectors, and different recreational activities, especially during summer and autumn, including sports and hunting. Free-ranging livestock occupies the montane meadows of the Pyrenean landscape during summer and autumn, between 1.500 and $2.500 \mathrm{~m}$, while beehives are located in the lower meadows.

\section{Data collection}

Since 2010 till 2017, we used camera-trapping methods to conduct bear activity monitoring during three seasons: spring (March 21st-Jun 20th), summer (Jun 21st-Sep 20th), and autumn (Sep 21st-Dec 20th). We defined two disturbance types according to the season: (1) intraspecific disturbance in spring, mainly through competition between dominant and vulnerable individuals during the mating season; and (2) human disturbance in summer and autumn, from touristic activities, extensive farming, and hunting within the bear distribution range. The monitoring was not continuous. We deployed an average of 48 camera traps $(\mathrm{SE}=15)$ per year throughout the brown bear distribution area. Most of the cameras were active for 275 days/ year; however, due to technical issues, the number of camera traps and the trapping days varied over the sampling period, ranging between 34 and 275 trapping days per year. We distributed the camera traps mainly in forested areas, attaching them on trees approximately $0.5-1.0 \mathrm{~m}$ above the ground. The cameras were active $24 \mathrm{~h}$ /day with a trigger mode (Fig. 1). Cameras shot at least a burst of three pictures when triggered, with the minimal delay time possible ( $<1 \mathrm{~min}$ ) to maximize the number of samples taken per captured individual. When multiple bear photographs were taken within a 30-min interval, unless individuals were clearly distinguishable, we considered this detection as a single individual, minimizing the non-independence of consecutive pictures (Ridout and Linkie 2009; Gerber et al. 2012; Foster et al. 2013; Monterroso et al. 2014). We used the following camera models: Reconyx (RC55, HCC500, and HCC600; Reconyx, Inc., Holmen, Wisconsin); Bushnell (Trail scout, Trophy cam HD, Trophy cam XLT, Trophy cam, and Natureview; Bushnell, Kansas City, Missouri, United States); Leafriver (Trail scan and IR 7SS); and ScoutGuard (SG550, SG550V, and SG580M). We inspected and changed the batteries and memory cards every 15 to 30 days.

Identification of the detected individuals (i.e., sex and age class) was assessed by analyzing genetically hair samples collected at hair-trapping stations located in front of the cameratraps. We located one hair-trapping station at 3-5 $\mathrm{m}$ in front of the camera-traps. To induce bear rubbing and maximize detection probabilities, we baited the hair-trapping stations with turpentine and beechwood tar. The hair-traps consisted of treetraps of two or three strands of barbed wire of approximately $0.3 \mathrm{~m}$ attached to the tree trunk and X-shaped at $0.3-1.5 \mathrm{~m}$ from the ground.

\section{Data analysis}

We analyzed bear activity pattern to determine the relationship with the following variables: daylight time interval; 
season (autumn, spring, and summer); sex class (female with offspring, solitary female, males), including adult and subadult individuals; and age class (adult: $\geq 4$, subadult: $<4$ ). We based the daylight time interval on solar time with the monthly daylight length differences and defined during equinox periods as night (1800-0559 h) and day (0600-1759 h). We estimated activity preferences at daily and seasonal scales. We conducted genetic analyses to identify the sex class and parentage assessment of the individuals, using microsatellite and SNPs markers from hair samples collected in the hairtraps. Further, we used the population genealogy to determine the age class of the detected individuals. The continuous genetic monitoring of the population since the first translocations in 1996 and 1997, together with its small size and geographical isolation, has allowed assessing paternal-offspring genealogies over time (see Quenette et al. 2018 "Suivi de l'ours brun dans les Pyrénées", Report of the Brown Bear Transboundary Monitoring Group. Results 2018). Pyrenean brown bear population descends from translocated bears, which sex and age was known before the reintroduction. Thus, the age and parentage of the individuals have been monitored over time. We used photo-trapping methods to identify new offspring presence in the population, supporting the assessment of the population genealogy. Adult females were usually detected on the camera traps together with their offspring that remained with them during the first 2 years of rearing. Consequently, the presence of new cubs was noted. In some cases, cubs were encountered in the second year after birth. We estimated their age based on the body size of the cub when first seen on the pictures. This annual monitoring has allowed constructing the genealogy of the population, including the determination of age and sex classes. We excluded individuals with undetermined both age and sex classes. Further, to control for the differences in camera detection (see below), we used data pooling. All the analyses were restricted to data sets with $>10$ activity samples. We pooled the data when activity distributions were not different across the season, daily period, sex class, and age class. To control for the experiment-wise error rate, we used an alpha level of 0.05 to determine statistical significance and applied a Bonferroni correction (Zar 1999).

We assessed daily activity patterns of bears and compared its temporal overlapping among three class groups: sex group (female with offspring vs. male, female with offspring vs. solitary female), age group (adult vs. subadult), and sex-age group (male and female with/without offspring adult vs. male and female subadult). However, due to the lower number of occurrences of juveniles, we were not able to estimate the avoidance level among seasons for the sex-age group. To evaluate the daily activity pattern, we applied the Overlap package (Meredith and Ridout 2018) for each independent detection, calculating the probability density function using the kernel density, followed by pairwise comparisons by estimating the coefficient of overlap. Overlapping coefficient $(\Delta)$ is an estimator that determines the area under the curve formed by taking the minimum of the two density functions at each time point and ranges from 0 (no overlap) to 1 (complete overlap) (Ridout and Linkie 2009; Linkie and Ridout 2011). We considered two estimators according to the sample size: $\Delta_{1}$ for samples $<75$ and $\Delta_{4}$ for samples $\geq 75$ (Meredith and Ridout 2018). To obtain the precision of this estimator, we computed a standard deviation from 10,000 bootstrap samples (Meredith and Ridout 2018). Thus, we used the overlapping coefficient to identify the avoidance level between the individuals, following the evaluation of Monterroso et al. (2014). We considered the following ranges of avoidance: (1) low avoidance, (2) medium avoidance, and (3) high avoidance ( $\Delta \geq 76,66 \leq \Delta \geq 75$, and $\Delta \leq 65$, respectively).

To describe the preference for a certain time of the day or season, we conducted Rayleigh test (Z) from Circular package (Lund et al. 2017), assessing whether or not individuals displayed a random record distribution across the season and daily period (Pratas-Santiago et al. 2017). Rayleigh test considers the uniformity of a certain record distribution through that period ( $Z$ ar 2010), where a higher $Z$ value means that data are concentrated around the mean and less evenly distributed (Pratas-Santiago et al. 2017). Further, to evaluate daily and seasonal differences in the temporal patterns between coexisting pairs of sex and age bear groups, we used multiple comparison Mardia-Watson-Wheeler test (MWW) (Batschelet 1981). Statistical analyses were conducted in R software, version 3.4.3 (R Core Team 2017).

\section{Results}

A total of 2253 independent detections of brown bears were recorded from 2200 effective trapping days. Photo-trapping cameras had an average of 84.38 trapping days with bear detections $(\mathrm{SE}=69.50)$ along the whole sampling period. We identified sex and age classes of the individuals in 1189 independent records. We recorded 768 independent detections of males and 421 independent detections of females (with offspring: $n=144$; solitary: $n=277)$, both adult $(n=1112)$ and subadults $(n=77)$.

As for time-period preference, bears were detected significantly more often during the nighttime period (Rayleigh test: $Z$ mean $=0.94, p<0.05$ ). The population activity pattern showed two activity peaks at $0600 \mathrm{~h}$ and $2200 \mathrm{~h}(>50 \%)$, and a lower detectability $(<10 \%)$ when disturbance caused by humans is higher $(1000-1800 \mathrm{~h})$. The results showed differences in activity patterns between various age and sex classes, mainly demonstrated by the presence of vulnerable individuals (Figs. 3 and 4). Considering sex groups comparisons, MWW test revealed that the presence of offspring determined sex differences in daily cycle pattern (MWW test, females 
with offspring vs. solitary females: $\mathrm{W}=17.06, n=431, p=$ 0.0002; females with offspring vs. males: $\mathrm{W}=36.354, n=$ 898, $p<0.005$; males vs. solitary females: $\mathrm{W}=4.695, n=$ $1049, p=0.09)$. At the daily scale, females with offspring selected more diurnal periods than solitary individuals (Figs. 2 and 4), showing medium avoidance level $\left(\Delta_{1} \leq\right.$ $0.70)$. Solitary females and males showed low avoidance patterns $\left(\Delta_{1} \geq 0.90\right)$. At the seasonal scale, sex groups showed high variance in detectability activity (Table 1). Generally, the number of detections was higher during spring, coinciding with increased segregation activity in all the sex groups (Fig. 4). While solitary individuals were mainly detected during the spring (females: $n$ spring $=138 ; n$ summer $=110 ; n$ autumn $=43$; males: $n_{\text {spring }}=439 ; n_{\text {summer }}=257 ; n$ autumn $=$ 62), females with offspring were detected more frequently during summer, with low intraspecific disturbance but high human presence ( $n$ spring $=24 ; n$ summer $=82 ; n$ autumn $=34$ ). In spring, females with offspring showed activity peaks in diurnal periods, at 0800-0900 $\mathrm{h}$ and $1800-2000 \mathrm{~h}$, with lower activity during $0300-0500 \mathrm{~h}$ and $1300-1500 \mathrm{~h}$. Females with offspring showed strong avoidance behavior toward males and solitary females during the nighttime (Fig. 4, Table 1). Nevertheless, solitary individuals showed lower activity in diurnal periods, at 0800-2000 h, with constant activity along nocturnal periods. In summer, while solitary individuals kept the nocturnal pattern, females with offspring increased diurnal activity at 1400-2100 h. In autumn, detectability during daylight hours (1700-2300 h) increased in all the sex classes, and females with offspring overlapped more with solitary individuals.
Table 1 Number of independent detections (n), coefficient of overlap $\left(\Delta_{4}\right)$, and Mardia-Watson-Wheeler test (MWW) among the activity patterns of coexistent groups of sex-class of brown bears (FWO: female with offspring; SF: solitary female; M: male), on a seasonal basis (spring: with high levels of intraspecific disturbance; summer and autumn: with high levels of human disturbance), in the Pyrenees; France, Spain, and Andorra, 2010-2017

\begin{tabular}{|c|c|c|c|c|c|c|c|c|c|}
\hline \multirow[t]{2}{*}{ Season } & \multirow[t]{2}{*}{ Class } & \multicolumn{4}{|l|}{$\mathrm{SF}$} & \multicolumn{4}{|l|}{ M } \\
\hline & & $n$ & W & $p$ & $\Delta_{4}$ & $n$ & W & $p$ & $\Delta_{4}$ \\
\hline \multirow[t]{2}{*}{ Spring } & FWO & 162 & 8.47 & $<0.05$ & 0.69 & 463 & 10.67 & $<0.05$ & 0.63 \\
\hline & SF & & & & & 577 & 1.02 & 0.60 & 0.92 \\
\hline \multirow[t]{2}{*}{ Summer } & FWO & 192 & 11.32 & $<0.05$ & 0.79 & 339 & 21.76 & $<0.05$ & 0.71 \\
\hline & SF & & & & & 367 & 2.14 & 0.34 & 0.91 \\
\hline \multirow[t]{2}{*}{ Autumn } & FWO & 77 & 0.08 & 0.96 & 0.75 & 96 & 7.46 & $<0.05$ & 0.69 \\
\hline & $\mathrm{SF}$ & & & & & 105 & 5.09 & 0.08 & 0.82 \\
\hline \multirow[t]{2}{*}{ Annual } & FWO & 431 & 17.06 & $<0.05$ & & 898 & 36.35 & $<0.05$ & \\
\hline & SF & & & & & 1049 & 4.70 & 0.10 & \\
\hline
\end{tabular}

The age groups at a daily scale showed differences in temporal patterns (MWW test, adults-subadults: $\mathrm{W}=12.58, n=$ 431, $p=0.0019$ ), where subadults strongly selected diurnal periods (adult: mean $\pm \mathrm{SE}=20.21 \pm 4.87$; subadults: mean \pm $\mathrm{SE}=46.56 \pm 9.22$; Fig. 3), having a medium avoidance level of the adult bears $\left(\Delta_{4}=0.70\right)$. Adult bears' activity decreased from 0900 to $1900 \mathrm{~h}$, while activity peaks of the subadult bears were between 1600 and $2000 \mathrm{~h}$, just before the activity peak of adult bears and coinciding with the most human disturbance. Diurnal activity of subadult individuals was higher
Fig. 2 Percentage of independent detections of brown bear according to the sex-class (solitary females, females with offspring, and males) over a $24-$ h cycle (night: $1800-0559$ h, day: 0600-1759 h) presented in two daily periods (day, dark gray; and night, light gray)

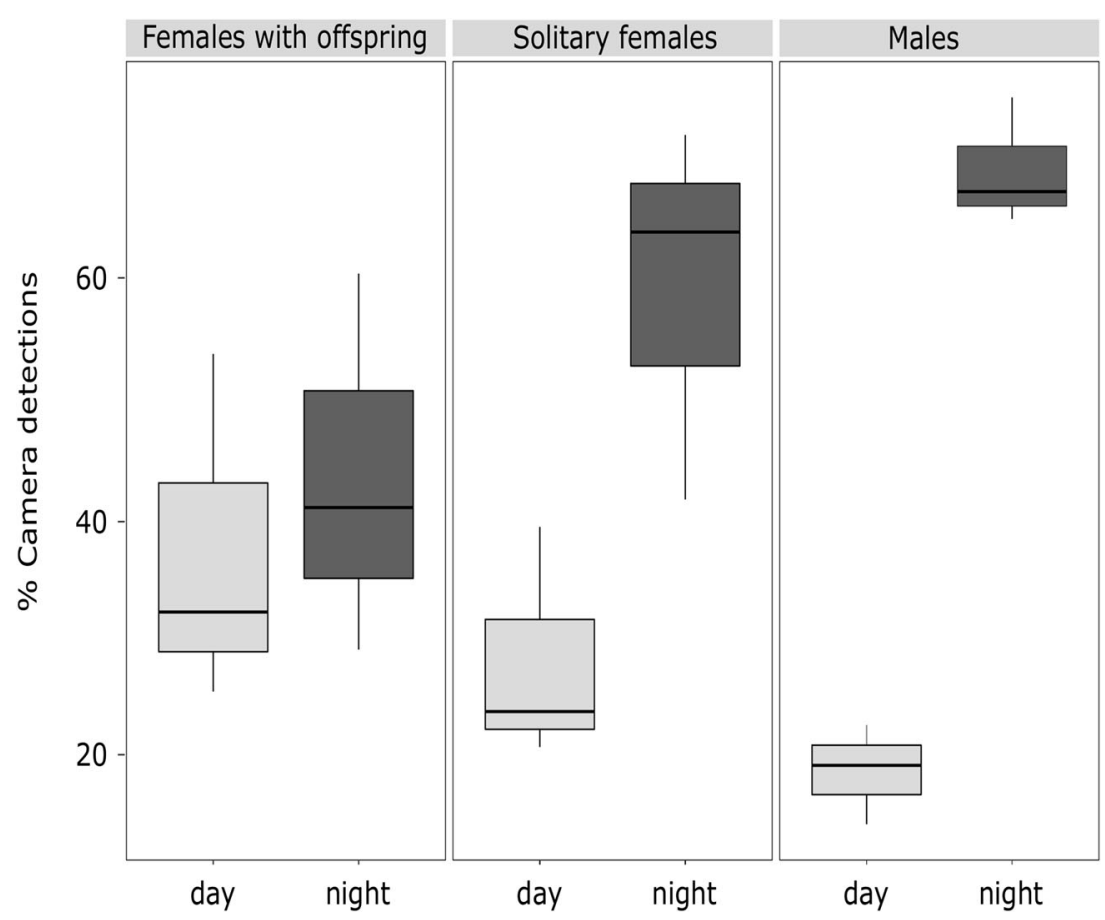


Fig. 3 General brown bear activity pattern and overlapping activity analysis $\left(\Delta_{1}\right)$ in relation to the sex-age group: a adult females vs. subadult females, $\mathbf{b}$ adult females vs. subadult males, c adult males vs. subadult females, and $\mathbf{d}$ adult males vs. subadult males. Black solid lines indicate adults and dotted lines indicate subadults. The activity records for each sex-age group were $n_{\text {Adult } \mathrm{F}}=373 ; n$ Adult $\mathrm{M}=739 ; n$ Subadult $\mathrm{F}=52 ; n$ Subadult $\mathrm{M}=25$ a

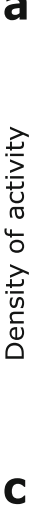

C - Adult M -.- Subadult F

$\Delta$

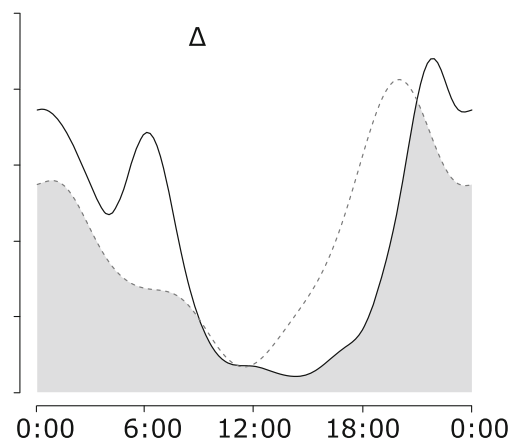
$\Delta$

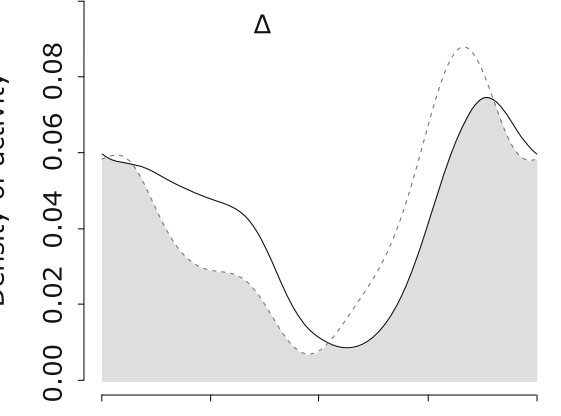

b — Adult F - - - Subadult M

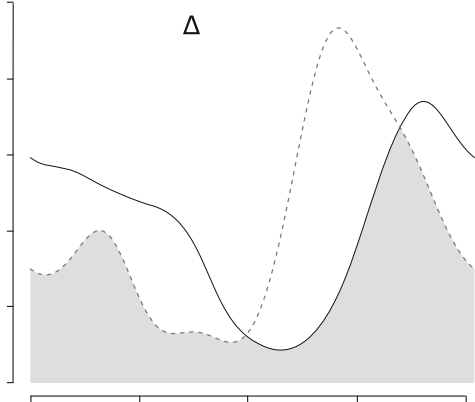

d — Adult M -.- Subadult M

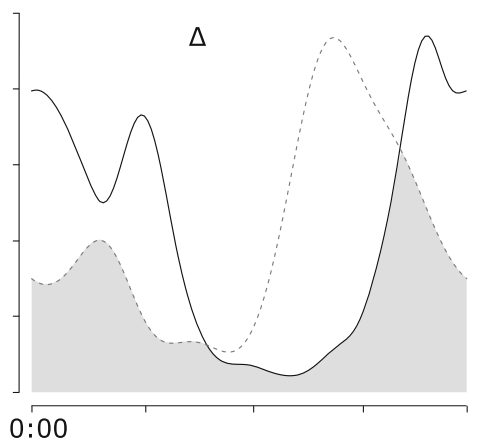

during the high intraspecific disturbance season, showing a higher avoidance level $\left(\Delta_{1}=0.58\right)(\mathrm{MWW}$ test, $\mathrm{W}=14.44$, $n=455, p=0.0007)$.

Comparison of activity patterns of sex-age groups showed that adult males vs. subadult males $\left(\Delta_{1}=0.56\right)$ and adult females vs. subadults males $\left(\Delta_{1}=0.67\right)$ had the lowest overlapping coefficients. Subadult males avoided adults during higher activity peaks (at $0500-0900 \mathrm{~h}$ and $2000-0030 \mathrm{~h}$ ). In contrast, the activity of subadult females was similar to the activity of adult individuals, being mainly concentrated between 1800 and $0600 \mathrm{~h}$ (subadult females vs. adult males: $\Delta_{1}=0.75$; and subadult females vs. adult females: $\Delta_{1}=$ 0.84) (Fig. 3). In general, in spring and summer, the number of detections of subadult bears of both sexes was higher than in autumn (subadult males: $n$ spring $=12 ; n$ summer $=10 ; n$ autumn $=2$; subadult females: $n$ spring $=26 ; n$ summer $=21 ; n$ autumn $=7$ ). Subadult females showed, equally among the seasons, more than $60 \%$ of the occurrences in a nocturnal period. In contrast, subadult males were more active during the day in spring and summer, while the only two occurrences recorded in autumn were nocturnal.

\section{Discussion}

Similar to other bear populations in Europe (for Croatia and Slovenia, Kaczensky et al. 2006; for Sweden, Ordiz et al. 2014), the Pyrenean bears showed high activity during nocturnal and crepuscular periods (Figs. 3 and 4). Further, females with offspring and subadults modified their nocturnal behavior to more diurnal under the presence of disturbances. In line with our expectations, solitary and adult individuals were mainly nocturnal or crepuscular, whereas vulnerable individuals (i.e., females with offspring and subadults) increased day-time activity. As we predicted based on anecdotal observations by fieldworkers in the Pyrenees (Palazón et al. unpubl. data), this behavior might be a strategy to avoid the risk of competition or predation. Daytime preference may (1) expose vulnerable individuals more frequently to humans (Kaczensky et al. 2006), especially during the high human activity periods (i.e., summer and autumn); and (2) increase random encounters with humans.

Carnivores modify their temporal activity patterns according to biological (i.e., sex or age) and external factors. This has been studied for a variety of species (e.g., Reynolds and Beecham 1980, for black bear; Foster et al. 2013, for puma and jaguar; Monterroso et al. 2014, for mesocarnivores; Munro et al. 2007; Penteriani et al. 2017; Zarzo-Arias et al. 2018, for brown bear). Anthropic pressure on European wild areas has promoted elusiveness strategies of wildlife. A known example is the variation of spatio-temporal activity responses (Ordiz et al. 2016). Most of the large carnivores in Europe have a long human persecution record. Consequently, it may have increased the vigilance and elusiveness behavior found in the current populations (Zedrosser et al. 2001; Martin et al. 2010; Ordiz et al. 2014; Hertel et al. 2016). Encounters between bears and humans in Europe have been boosted by increasing outdoor activities (Kaczensky et al. 2006; Tucker 


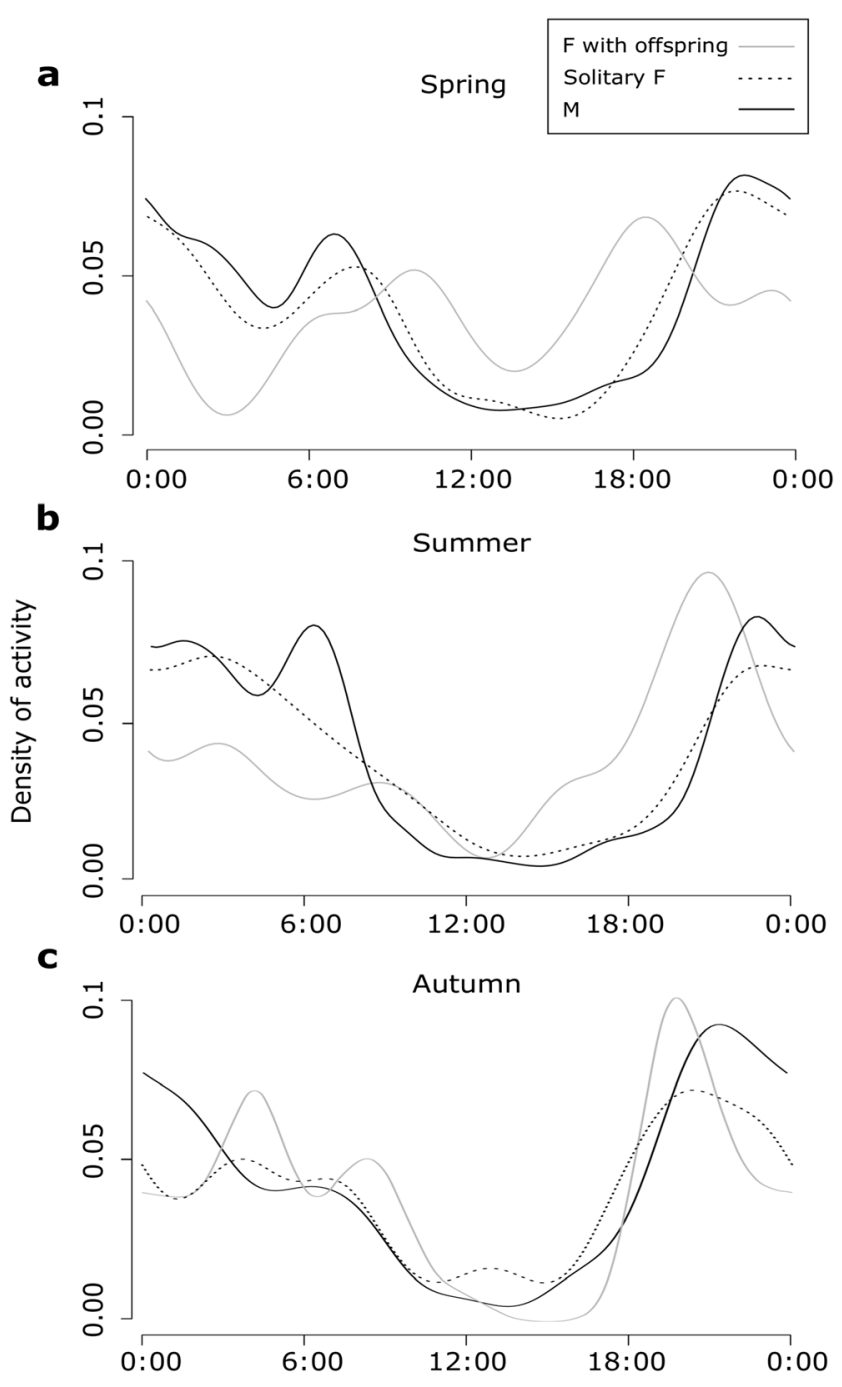

Fig. 4 Seasonal brown bear activity pattern according to the sex classes: a the daily activity pattern during spring $\left(n_{\mathrm{F}}\right.$ with offspring $=24 ; n_{\text {Solitary } \mathrm{F}}=$ $138 ; n_{\mathrm{M}}=439$ activity records), $\mathbf{b}$ the daily activity pattern during summer $\left(n_{\mathrm{F}}\right.$ with offspring $=82 ; n_{\text {Solitary } \mathrm{F}}=110 ; n_{\mathrm{M}}=257$ activity records), and $\mathbf{c}$ the daily activity pattern during autumn $(n$ F with offspring $=34 ; n$ Solitary $\mathrm{F}=43 ; n_{\mathrm{M}}=62$ activity records). Gray solid lines indicate females with offspring ( $\mathrm{F}$ with offspring), black solid lines indicate males (M), and dotted lines indicate solitary females (Solitary F)

et al. 2018). Thus, human-caused disturbances, especially the use of natural areas and hunting activities, may be perceived by animals as a risk. Consequently, it may influence their spatio-temporal activity patterns (Hertel et al. 2016). In Pyrenees, in comparison with other regions of Europe, beartargeted hunting is prohibited; however, bears may be disturbed during the hunting seasons of other groups of animals (e.g., ungulates). As a mechanism of elusiveness, individuals may change their activity to nocturnal periods.

The Pyrenean brown bear population was almost extinct in 1996, and after the reintroduction of 11 individuals, the current population descends from bears translocated from Slovenia (Piédallu et al. 2016). In our research, we assumed that relocated individuals maintained the same nocturnal activity pattern as the Slovenian population (Kaczensky et al. 2006). Many studies on brown bear behavior evidence that changes in the activity might be a result of social learning between mother and cubs (Nielsen et al. 2013; Hopkins 2013; Morehouse et al. 2016). Consequently, we consider that the nocturnal behavior of relocated females' offspring might have been acquired through social learning during the first years of the mother-offspring relationship. Future research would further test the impact of social learning and the environment on bear cubs' behavior in the Pyrenees.

Despite the effectiveness of adopting a nocturnal behavior as a strategy to avoid human disturbance (MacHutchon et al. 1998; Rode et al. 2006), vulnerable bears increased diurnal activity under intraspecific disturbance. Further, the major avoidance of nocturnal activity by vulnerable bears in the Pyrenees was observed during the mating season. Avoidance of intraspecific competition by vulnerable individuals has been widely described in carnivores (Steyaert et al. 2013; Wielgus et al. 2013). We believe that circadian variations in Pyrenean bears might influence intraspecific encounters. This might facilitate mating encounters or minimize competition risk (Dahle and Swenson 2003; Rode et al. 2006). Overlap of activity periods of solitary bears was higher during the mating season, possibly to increase the chances of mating encounters (Sahlén et al. 2015). However, our results showed that females with offspring and subadults were mainly detected during the day. Several reports on brown bears in Europe and North America indicated that females with offspring modify their activity to more diurnal (Gunther 1990; Klinka and Reimchen 2002). Diurnal behavior might minimize male encounters' probabilities and infanticide risk (McLellan 2005; Bellemain et al. 2006a; Ordiz et al. 2011; Steyaert et al. 2013). With the infanticide, males create mating opportunities with victimized mothers (Steyaert et al. 2016). As a result, females evolve counterstrategies to defend their cubs (Bellemain et al. 2006b). In the Pyrenean population, non-parental infanticide was observed in two cases in 2011 and 2016 (Palazón et al. 2016). Possibly, our findings regarding the activity modulation of the mothers are the result of anti-infanticide responses during high-intensity risk periods.

Individual learning in bears provides a higher wariness toward risk situations and may be influenced by previous negative experiences. Our study showed a diurnal preference in subadult bears. It is often assumed that activity variations of inexperienced bears might be a strategy to evade competition with adult individuals, especially during their higher activity peaks. However, this activity in subadult bears is not constant over the year. Among all the subadults, females showed a low avoidance level to adult males, especially during the mating season. Low elusiveness found in subadult females may be explained by early primiparity. Early primiparity exists in brown bear females, but these 
cases are rare (e.g., for Sweeden, see Zedrosser et al. 2009). In the Pyrenees, there are cases of advanced primiparity cases in young females ( $<4$ years) (Palazón et al. unpubl. data). Furthermore, intra-sexual competition is often described in many animal groups, where dominant individuals suppress the reproduction of younger females (Støen et al. 2006). In bear populations, young females establish their home ranges close to their progenitors, increasing the chances of reproduction suppression (McLellan 2005; Bellemain et al. 2006a). Due to the small density and the large distribution range in the Pyrenees, we believe that chances of female-female encounters are low. This fact allows females to get an early reproductive maturation. Thus, activity overlapping of the subadult females with adult males might facilitate mating encounters. An alternative explanation of this activity overlapping might be that philopatric young females learn the behavioral patterns from their mothers, imitating their nocturnal activity. Diurnal preference by subadult males provides higher awareness of intraspecific risk with dominant bears. Also, subadult males tend to disperse and travel long distances (McLellan 2005; Bartoń et al. 2019), and this fact may also decrease the chances of antagonistic interactions. We have no movement data from subadult individuals in the studied population; however, we suspect that their exploratory behavior during the daylight may prevent male-male competition (Andersson 1994; Bellemain et al. 2006a).

Even if vulnerable bears reduce the negative stimuli from dominant bears, human disturbance may continue affecting diurnal individuals. The growing presence of humans in the bear-inhabited areas, especially during summer and autumn, increases chances of human-bear encounters. However, reduction of diurnal detection during autumn by all of the classes may reduce this risk. It is important to improve our knowledge on how translocated animals behave in new environments. As the behavioral strategies behind disturbance avoidance are becoming well understood, future studies might focus on other small, isolated but natural bear populations in humanmodified landscapes (e.g., Zarzo-Arias et al. 2018), and help to establish optimal management interventions during translocations, human-bear conflicts prevention actions, and reduction of the risk of human-bear encounters.

Acknowledgments We acknowledge the technical assistance of employees, students, and volunteers who helped with data collection, and Brown bear Foundation (Fundación Oso Pardo, FOP), Universitat de Lleida (UdL), and Forestal Catalana (FORCAT) for their support. We thank the Carpathian Brown Bear Project team from the Institute of Nature Conservation of the Polish Academy of Sciences in Poland for the contributions to this manuscript, the advice in the statistical analysis and the helpful revisions offered.

Availability of data and material The data that support the findings of this study are available from the corresponding authors upon reasonable request.
Funding information This research was financially supported by the Regional Government of Catalonia, Spain; French Agency of Biodiversity (Office Français de la Biodiversité), France; General Council of Aran, Spain; and Government of Aragon, Spain. The material and work was supported by the Piros Life Project from the LIFE program (LIFE 13 NAT/ES/001394) during 2014-2017. AP was partly supported by the BearConnect project funded by the National Science Centre, Poland, under the BiodivERsA call (2016/22/Z/NZ8/00121).

\section{Compliance with ethical standards}

Conflict of interest The authors declare that they have no conflict of interest.

Ethics approval All applicable international, national, and/or institutional guidelines for the care and use of animals were followed. All procedures performed in studies involving animals were in accordance with the ethical standards of the Animal Care Committee from the Department of Territory and Sustainability, Regional Catalonia Government (no. 2680).

Open Access This article is licensed under a Creative Commons Attribution 4.0 International License, which permits use, sharing, adaptation, distribution and reproduction in any medium or format, as long as you give appropriate credit to the original author(s) and the source, provide a link to the Creative Commons licence, and indicate if changes were made. The images or other third party material in this article are included in the article's Creative Commons licence, unless indicated otherwise in a credit line to the material. If material is not included in the article's Creative Commons licence and your intended use is not permitted by statutory regulation or exceeds the permitted use, you will need to obtain permission directly from the copyright holder. To view a copy of this licence, visit http://creativecommons.org/licenses/by/4.0/.

\section{References}

Alibhai S, Jewell Z, Evans J (2017) The challenge of monitoring elusive large carnivores: an accurate and cost-effective tool to identify and sex pumas (Puma concolor) from footprints. PLoS One 12: e0172065. https://doi.org/10.1371/journal.pone.017206

Andersson M (1994) Sexual selection. Princeton University Press, Princeton

Bartoń KA, Zwijacz-Kozica T, Zięba F, Sergiel A, Selva N (2019) Bears without borders: long-distance movement in human-dominated landscapes. Glob Ecol Conserv 17:e00541. https://doi.org/10. 1016/j.gecco.2019.e00541

Batschelet E (1981) Circular statistics in biology. Academic Press, London

Bellemain E, Swenson JE, Taberlet P (2006a) Mating strategies in relation to sexually selected infanticide in a non-Soc. Ethology 112 : 238-246

Bellemain E, Zedrosser A, Manel S, Waits LP, Taberlet P, Swenson JE (2006b) The dilemma of female mate selection in the brown bear, a species with sexually selected infanticide. Proc R Soc B Biol Sci 273:283-291. https://doi.org/10.1098/rspb.2005.3331

Bombieri G, Nanni V, Delgado MM, Fedriani JM, López-Bao JV, Pedrini P, Penteriani V (2018) Content analysis of media reports on predator attacks on humans: toward an understanding of human risk perception and predator acceptance. Bioscience 68:577-584. https://doi.org/10.1093/biosci/biy072

Brook LA, Johnson CN, Ritchie EG (2012) Effects of predator control on behaviour of an apex predator and indirect consequences for 
mesopredator suppression. J Appl Ecol 49:1278-1286. https://oi. org/10.1111/j.1365-2664.2012.02207.x

Chapron G, Wielgus R, Quenette PY, Camarra JJ (2009) Diagnosing mechanisms of decline and planning for recovery of an endangered brown bear (Ursus arctos) population. PLoS One 4:e7568. https:// doi.org/10.1371/journal.pone.0007568

Dahle B, Swenson JE (2003) Seasonal range size in relation to reproductive strategies in brown bears Ursus arctos. J Anim Ecol 72:660 667. https://doi.org/10.1046/j.1365-2656.2003.00737.x

Ebensperger LA (1998) Strategies and counterstrategies to infanticide in mammals. Biol Rev 73:321-346. https://doi.org/10.1111/j.1469185X.1998.tb00034.x

Fortin JK, Rode KD, Hilderbrand GV, Wilder J, Farley S, Jorgensen C, Marcot BG (2016) Impacts of human recreation on brown bears (Ursus arctos): a review and new management tool. PLoS One 11: 1-26. https://doi.org/10.1371/journal.pone.0141983

Foster VC, Sarmento P, Sollmann R, Tôrres N, Jácomo ATA, Negrões N, Fonseca C, Silveira L (2013) Jaguar and puma activity patterns and predator-prey interactions in four brazilian biomes. Biotropica 45: 373-379. https://doi.org/10.1111/btp.12021

Frank SC, Ordiz A, Gosselin J, Hertel A, Kindberg J, Leclerc M, Pelletier F, Steyaert SMJG, Støen O-G, Van de Walle J, Zedrosser A, Swenson JE (2017) Indirect effects of bear hunting: a review from Scandinavia. Ursus 28:150-164

Gerber BD, Karpanty SM, Randrianantenaina J (2012) Activity patterns of carnivores in the rain forests of Madagascar: implications for species coexistence. J Mammal 93:667-676. https://doi.org/10. 1644/11-mamm-a-265.1

Gunther KA (1990) Visitor impact on grizzly bear activity in Pelican Valley, Yellowstone National Park. Bears Their Biol Manag 8:73. https://doi.org/10.2307/3872904

Hertel AG, Zedrosser A, Mysterud A, Støen OG, Steyaert SMJG, Swenson JE (2016) Temporal effects of hunting on foraging behavior of an apex predator: do bears forego foraging when risk is high? Oecologia 182:1019-1029. https://doi.org/10.1007/s00442-0163729-8

Hopkins JB (2013) Use of genetics to investigate socially learned foraging behavior in free-ranging black bears. J Mammal 94:1214-1222. https://doi.org/10.1644/13-mamm-a-009.1

Hrdy SB (1979) Infanticide among animals: a review, classification, and examination of the implications for the reproductive strategies of females. Ethol Sociobiol 1:13-40. https://doi.org/10.1016/01623095(79)90004-9

Kaczensky P, Huber D, Knauer F, Roth HU, Wagner A, Kusak J (2006) Activity patterns of brown bears (Ursus arctos) in Slovenia and Croatia. J Zool 269:474-485. https://doi.org/10.1111/j.1469-7998. 2006.00114.x

Klinka DR, Reimchen TE (2002) Nocturnal and diurnal foraging behaviour of brown bears (Ursus arctos) on a salmon stream in coastal British Columbia. Can J Zool 80:1317-1322. https://doi.org/10. 1139/z02-123

Leuchtenberger C, Zucco CA, Ribas C, Magnusson W, Mourão G (2014) Activity patterns of giant otters recorded by telemetry and camera traps. Ethol Ecol Evol 26:19-28. https://doi.org/10.1080/03949370. 2013.821673

Linkie M, Ridout MS (2011) Assessing tiger-prey interactions in Sumatran rainforests. J Zool 284:224-229. https://doi.org/10.1111/ j.1469-7998.2011.00801.x

Lund U, Agostinelli C, Arai H, Gagliardi A, Garcia Portugues E, Giunchi D, Irisson JO, Pocernich M, Rotolo F (2017) Package "circular"

MacHutchon GA, Himmer S, Davis H, Gallagher M (1998) Temporal and spatial activity patterns among coastal bear populations. Ursus 10:539-546. https://doi.org/10.2307/3873166

Martin J, Basille M, Van Moorter B, Kindberg J, Allainé D, Swenson JE (2010) Coping with human disturbance: spatial and temporal tactics of the brown bear (Ursus arctos). Can J Zool 88:875-883. https:// doi.org/10.1139/Z10-053

Martin J, Revilla E, Quenette PY, Naves J, Allainé D, Swenson JE (2012) Brown bear habitat suitability in the Pyrenees: transferability across sites and linking scales to make the most of scarce data. J Appl Ecol 49:621-631. https://doi.org/10.1111/j.1365-2664.2012.02139.x

McLellan BN (2005) Sexually selected infanticide in grizzly bears: the effects of hunting on cub survival. Ursus 16:141-156. https://doi. org/10.2192/1537-6176(2005)016[0141:ssiigb]2.0.co;2

Meredith M, Ridout M (2018) Estimates of coefficient of overlapping for animal activity patterns. $\mathrm{R}$ package version 0.3 .2

Monterroso P, Alves PC, Ferreras P (2014) Plasticity in circadian activity patterns of mesocarnivores in southwestern Europe: implications for species coexistence. Behav Ecol Sociobiol 68:1403-1417. https:// doi.org/10.1007/s00265-014-1748-1

Morehouse AT, Graves TA, Mikle N, Boyce MS (2016) Nature vs nurture: evidence for social learning of conflict behaviour in grizzly bears. PLoS One 11:e0165425. https://doi.org/10.1371/journal. pone. 0165425

Munro RHM, Nielsen SE, Price MH, Stenhouse GB, Boyce MS (2007) Seasonal and diel patterns of grizzly bear diet and activity in westCentral Alberta. J Mammal 87:1112-1121. https://doi.org/10.1644/ 05-mamm-a-410r3.1

Nielsen SE, Shafer ABA, Boyce MS, Stenhouse GB (2013) Does learning or instinct shape habitat selection? PLoS One 8:e53721. https:// doi.org/10.1371/journal.pone.0053721

Olson TL, Squibb RC, Gilbert BK (1998) Brown bear diurnal activity and human use: a comparison of two salmon streams. Ursus 10:547-555

Ordiz A, Støen O-G, Delibes M, Swenson JE (2011) Predators or prey? Spatio-temporal discrimination of human-derived risk by brown bears. Oecologia 166:59-67. https://doi.org/10.1007/s00442-0111920-5

Ordiz A, Bischof R, Swenson JE (2013) Saving large carnivores, but losing the apex predator? Biol Conserv 168:128-133

Ordiz A, Kindberg J, Sæbø S, Swenson JE, Støen OG (2014) Brown bear circadian behavior reveals human environmental encroachment. Biol Conserv 173:1-9. https://doi.org/10.1016/j.biocon.2014.03. 006

Ordiz A, Saebø S, Kindberg J, Swenson JE, Støen OG (2016) Seasonality and human disturbance alter brown bear activity patterns: implications for circumpolar carnivore conservation? Anim Conserv 20:5160. https://doi.org/10.1111/acv.12284

Packer C (2001) Infanticide Is No Fallacy. Am Anthropol 102:829-831. https://doi.org/10.1525/aa.2000.102.4.829

Palazón S, Quenette PY, Afonso I (2016) Riesgo de infanticidio en la población de oso pardo de los Pirineos Centrales debido a la liberación de una macho adulto en la primavera de 2016 procedente de Eslovenia. Barcelona [In Spanish]

Penteriani V, Delgado MM, Pinchera F, Naves J, Fernández-Gil A, Kojola I, Härkönen S, Norberg H, Frank J, Fedriani JM, Sahlén V, Støen OG, Swenson JE, Wabakken P, Pellegrini M, Herrero S, López-Bao JV (2016) Human behaviour can trigger large carnivore attacks in developed countries Sci Rep 6. https://doi.org/10.1038/ srep20552

Penteriani V, López-Bao JV, Bettega C, Dalerum F, Delgado MM, Jerina K, Kojola I, Krofel M, Ordiz A (2017) Consequences of brown bear viewing tourism: a review. Biol Conserv 206:169-180. https://doi. org/10.1016/j.biocon.2016.12.035

Piédallu B, Quenette P-Y, Mounet C, Lescureux N, Borelli-Massines M, Dubarry E, Camarra JJ, Gimenez O (2016) Spatial variation in public attitudes towards brown bears in the French Pyrenees. Biol Conserv 197:90-97. https://doi.org/10.1016/j.biocon.2016.02.027

Piédallu B, Quenette P-Y, Bombillon N, Gastineau A, Miquel C, Gimenez O (2017) Determinants and patterns of habitat use by the brown bear Ursus arctos in the French Pyrenees revealed by 
occupancy modelling. Oryx 53:334-343. https://doi.org/10.1017/ S0030605317000321

Pratas-Santiago LP, Gonçalves ALS, Nogueira AJA, Spironello WR (2017) Dodging the moon: the moon effect on activity allocation of prey in the presence of predators. Ethology 123:467-474. https:// doi.org/10.1111/eth.12617

Quenette PY, Camarra JJ, Sentilles J, Vanpé C, Steinmetz J, Douette M, Palazón S, Casanovas Urgel R, Servent A, Lampreave G, Solà J, Alcantara M, Jato R, Puente J, Artazkotz Colomo R, Giralda G, Afonso Jordana I, Palomero G, 2018. Report of the Brown bear transboundary monitoring group. Results 2018. Vielha (Val d'Aran, Spain)

R Core Team (2017) R: a language and environment for statistical computing. R Foundation for Statistical Computing. Vienna Austria. https://www.R-project.org/

Reynolds DG, Beecham JJ (1980) Home range activities and reproduction of black bears in West-Central Idaho. Bears Their Biol Manag 4:181-190

Ridout MS, Linkie M (2009) Estimating overlap of daily activity patterns from camera trap data. J Agric Biol Environ Stat 14:322-337. https://doi.org/10.1198/jabes.2009.08038

Rode KD, Farley SD, Robbins CT (2006) Sexual dimorphism, reproductive strategy, and human activities determine resource use by brown bears. Ecology 87:2636-2646

Sahlén V (2013) Encounters between brown bears and humans in Scandinavia-contributing factors, bear behavior and management perspectives. PhD Dissertation, Norwegian University of Life Sciences

Sahlén V, Ordiz A, Swenson JE, Støen OG (2015) Behavioural differences between single scandinavian brown bears (Ursus arctos) and females with dependent young when experimentally approached by humans. PLoS One 10:1-16. https://doi.org/10.1371/journal.pone. 0121576

Sentilles J, Camarra JJ, Vanpé C, Quenette PY (2018) Suivi de l'ours brun dans les Pyrénées françaises. Villeneuve de Rivière [In French]

Steyaert SMJG, Kindberg J, Swenson JE, Zedrosser A (2013) Male reproductive strategy explains spatiotemporal segregation in brown bears. J Anim Ecol 82:836-845. https://doi.org/10.1111/13652656.12055

Steyaert SMJG, Zedrosser A, Elfström M, Ordiz A, Leclerc M, Frank SC, Kindberg J, Støen OG, Brunberg S, Swenson JE (2016) Ecological implications from spatial patterns in human-caused brown bear mortality. Wildl Biol 22:144-152. https://doi.org/10.2981/wlb.00165

Støen OG, Zedrosser A, Wegge P, Swenson JE (2006) Socially induced delayed primiparity in brown bears Ursus arctos. Behav Ecol Sociobiol 61:1-8. https://doi.org/10.1007/s00265-006-0231-z
Stone AA, Schwartz JE, Schkade D, Schwarz N, Krueger A, Kahneman D (2006) A population approach to the study of emotion: diurnal rhythms of a working day examined with the day reconstruction method. Emotion 6:139-149. https://doi.org/10.1037/1528-3542.6. 1.139

Swenson JE (1999) Does hunting affect the behavior of brown bears in Eurasia? Ursus 11:157-162. https://doi.org/10.2307/3872997

Treves A, Karanth KU (2003) Human-carnivore conflict and perspectives on carnivore management worldwide. Conservation Biology, In, pp 1491-1499

Tucker MA, Böhning-gaese K, Fagan WF et al (2018) Moving in the Anthropocene: global reductions in terrestrial mammalian movements. Science (80-) 469:466-469

Wiegand T, Knauer F, Kaczensky P, Naves J (2004) Expansion of brown bears (Ursus arctos) into the eastern Alps: a spatially explicit population model. Biodivers Conserv 13:79-114

Wielgus RB, Morrison DE, Cooley HS, Maletzke B (2013) Effects of male trophy hunting on female carnivore population growth and persistence. Biol Conserv 167:69-75. https://doi.org/10.1016/j. biocon.2013.07.008

Woodroffe R, Thirgood S, Rabinowitz A (2005) People and wildlife. Cambridge University Press, Cambridge

Zar JH (1999) Biostatistical analysis, 4th edn. Prentice Hall, Pearson, Upper Saddle River

Zar JH (2010) Biostatistical analysis. Prentice-Hall, Pearson, Upper Saddle River

Zarzo-Arias A, Delgado MM, Ordiz A, García Díaz J, Cañedo D, González MA, Romo C, Vázquez García P, Bombieri G, Bettega C, Russo LF, Cabral P, García González R, Martínez-Padilla J, Penteriani V (2018) Brown bear behaviour in human-modified landscapes: the case of the endangered Cantabrian population, NW Spain. Glob Ecol Conserv 16:e00499. https://doi.org/10.1016/j. gecco.2018.e00499

Zedrosser A, Dahle B, Swenson JE, Gerstl N (2001) Status and management of the brown bear in Europe. Ursus 12:9-20

Zedrosser A, Dahle B, Støen OG, Swenson JE (2009) The effects of primiparity on reproductive performance in the brown bear. Oecologia 160:847-854. https://doi.org/10.1007/s00442-009$1343-8$

Publisher's note Springer Nature remains neutral with regard to jurisdictional claims in published maps and institutional affiliations. 